\title{
Empirical Asset Pricing-Saudi Stylized Facts and Evidence
}

\author{
Wesam Mohamed Habib \\ The University of Business and Technology, Jeddah, Kingdom of Saudi Arabia
}

\begin{abstract}
This paper estimates proxy specifications of a five-factor asset pricing model to produce stylized facts of the Saudi capital market and test an arbitrage pricing theory (APT) model. The data set is the panel of 20 most actively traded firms, excluding firms with negative book value of equity. The contribution to the extant literature is three-fold: (1) organizing Saudi market data based on beta and firm-specific fundamentals, namely, growth, value, accounting earnings, and equity investments; (2) conducting a parsimony analysis within the theoretical framework of APT; and (3) quantifying the information risk facing the marginal investor by decomposing earnings into cash flows and accruals and investigating respective loadings in an unrestricted version of the parsimonious specification. Proxy asset pricing specifications, though intuitively appealing, are scant due to lack of theoretical frameworks and misguided significance tests of factor loadings. Throughout, this issue is addressed by keeping the empirical analysis under describing market facts and testing an APT model. The study concludes with a significant empirical explanation that specifies average returns in terms of the covariance risk and accounting accruals.
\end{abstract}

Keywords: asset pricing, factor models, APT

\section{Introduction}

This paper employs a proxy model instructed by the five-factor model of Fama and French (2015). The objective is to produce stylized facts of the Saudi capital market in terms of documenting empirical regularities in average returns. Both restricted and unrestricted versions of the proxy model are estimated and APT tests are performed coupled with documenting a loading for the information risk in the Saudi market. As opposed to a factor asset pricing model where the right-hand side variables are respective portfolio premiums, a proxy model describes excess returns with state variables defined with respect to the right-hand side variables of a particular factor model. In fact, a proxy model implies a particular factor model. This means that: (1) A proxy model is a sufficiency for a factor model; (2) a factor model is a necessity for a proxy model; and (3) by modus tollens, absence of a factor model implies absence of a proxy model. The preceding logic is established as it greatly frames the underlying empirical analysis in this paper.

Fama and French $(1993 ; 1995 ; 2015)$ maintained the empirical style they pioneered in the seminal study and the updated versions. Considered, by far, the most influential paper in finance in the last 30 years, Fama and French (1993) presented three-factor explanations of many asset pricing anomalies by taking market research away from the traditional pure hypothesis testing and into directly learning from data. Their approach, which had centered on the extent to which factors may contribute economically significant information above that

Wesam Mohamed Habib, Ph.D., assistant professor of finance and university coordinator of international affairs at the University of Business and Technology, Jeddah, Kingdom of Saudi Arabia.

Correspondence concerning this article should be addressed to Wesam Mohamed Habib, P.O. Box 110200, Jeddah 21361, Kingdom of Saudi Arabia. 
replicated in valuation, eventually earned Eugene Fama the 2013 memorial Nobel Prize in economic science.

In addition to the time-honored three factors of: (1) the excess return of the market portfolio over the risk-free rate; (2) the difference between the returns on a portfolio of small stocks and large stocks (SMB); and (3) the difference between the returns on a portfolio of high and low book-to-market stocks (HML), Fama and French (2015) entertained two more factors: (1) the difference between the returns on a portfolio of robust and weak accounting earnings and (2) the difference between the returns on a portfolio of conservative and aggressive equity investments.

As noted in order, factor models are typically rejected by the $F$-test of Gibbons, Ross, and Shanken (1989). Those empirical models, however, are designed to capture empirical regularities and so the primary concern is with the economic significance of parameter estimates (as opposed to the statistical significance). This is clearly unlike traditional asset pricing models, e.g., Sharpe's CAPM (1964), Merton's ICAPM (1973), and Ross' APT (1976a; 1976b), which produce risk-based theoretical frameworks of the average returns data generating process. Nonetheless, factor models can be turned into testable statements under the umbrella of APT. To reiterate, so long as state variables can proxy for the right-hand side variables of the factor model, APT allows for meaningful tests of the proxy model's parameter estimates. This is so paramount for this study that it exclusively instructs a mixed and step-wise research. In the first step, stylized facts are produced by estimating two data organization models instructed by Fama and French (2015), one restricted and the other unrestricted. In the second step, the two models are tested within an APT theoretical framework.

The rest of the paper is organized as follows: (1) background and development of empirical models; (2) empirical analysis; and (3) conclusions.

\section{Background and Development of Empirical Models}

Prior to Fama and French (1993), many published empirical tests have concluded that, in addition to beta, there are factors that significantly explain the cross-sectional variation of returns. Black, Jensen, and Scholes (1972) showed that though the empirical market line is positively sloped, the intercept term is 9.79 standard deviations away from the null CAPM zero mean, a fact which leads to their rejection of the CAPM contending that the market model is misspecified and that factors other than beta may be relevant. Basu (1977) documented that low P/E portfolios earn returns higher than the CAPM. Rosenberg and Marathe (1979) illustrated that adding variables, such as dividend yield, trading volume, and firm size, provide better predictions of beta and wash off much of the measurement error. Banz (1981) and Reinganum (1981) reported that small firms tend to earn returns higher than what could be explained by the CAPM. Litzenberger and Ramaswamy (1979) provided evidence that returns are positively correlated with dividend yields. Gibbons (1982) rejected the CAPM by testing a restriction implied by Black's two-factor version (1972) on the merely statistical market model.

Aware of the strong negative correlation of -0.988 between size and beta, Fama and French (1993) sorted asset returns from 1963 to 1990 for all NYSE and AMEX stocks based on size (as measured by the natural logarithm of equity market capitalization) and beta (as estimated using the value-weighted portfolio of NYSE, AMEX, and NASDAQ stocks as regressor). As such, in a two-pass portfolio sort, Fama and French (1993) separated beta and size effects on returns and showed that: (1) When sorts are size-based, the relationship between returns and both beta and size are clearly pronounced; and (2) when sorts are beta-based, the relationship is tenuous. Fama and French (1993) thus showed that a linear two-factor model is simply 
misspecified and suggested a multifactor model. They concluded that size and the ratio of book-to-market value of equity replace beta altogether in explaining stock returns.

Fama and French (1995) offered three-factor explanations of many anomalies and focused the market research onto directly learning from data and systematically documenting stylized facts (empirical regularities or patterns) that are evident in asset prices in large, representative samples. However, a significant literature (e.g., Haugen \& Baker, 1996; Cohen, Gompers, \& Vuolteenaho, 2002; Titman, Wei, \& Xie, 2004; Fama \& French, 2006; 2008) documented that much of the variation in average returns left unexplained by the three factors is due to profitability and investments. This led Fama and French (2015) to add profitability and investment to beta, growth, and value. Fama and French (2015) concluded by suggesting that value (i.e., HML) is redundant and that a four-factor model that drops HML performs as well as the five-factor model.

\section{Empirical Analysis}

This paper adheres to a mixed research paradigm through which it starts with a descriptive five-factor proxy to produce stylized facts and then proceeds into a quantitative study where APT tests are performed via estimating restricted and unrestricted versions of a parsimonious five-factor proxy.

\section{Data Selection}

The data set is the 2011-2014 panels of the most actively traded 20 firms in the KSA capital market, excluding firms with negative book value of equity in order to mitigate the presence of outliers and guarantee robust parameter estimates in accordance with a Gauss-Markov specification of the error term.

\section{Stylized Facts: Data Organization}

In this study, Saudi market data are organized according to two models based on whether accounting earnings were replicated in total or decomposed into cash flows and accruals.

Table 1

\section{Descriptive Statistics}

\begin{tabular}{lllllllll}
\hline Statistic & Returns & Beta & Growth & Value & Earnings & Cash flows & Accruals & Investments \\
\hline Mean & -0.24386 & 1.000006 & 11.00758 & 5.249383 & 0.018112 & 0.014072 & -0.43821 & -0.00851 \\
Standard error & 0.081866 & 0.255308 & 0.222587 & 0.387428 & 0.036355 & 0.005379 & 0.188116 & 0.023633 \\
Median & -0.30108 & 1.177928 & 11.17489 & 5.124092 & 0.012746 & 0.003703 & -0.28733 & 0.007095 \\
Standard deviation & 0.366114 & 1.141774 & 0.99544 & 1.732632 & 0.162584 & 0.024054 & 0.84128 & 0.105688 \\
Sample variance & 0.13404 & 1.303648 & 0.990902 & 3.002013 & 0.026433 & 0.000579 & 0.707752 & 0.01117 \\
Kurtosis & 1.258528 & 1.569481 & -0.76931 & -0.89521 & 5.915076 & 3.535951 & 14.48126 & 7.407545 \\
Skewness & -0.60439 & 0.697246 & -0.12251 & 0.296573 & 0.84857 & 1.8252 & -3.6156 & -0.87508 \\
Range & 1.508646 & 4.831187 & 3.448409 & 5.703472 & 0.903769 & 0.100916 & 4.134519 & 0.614339 \\
Minimum & -1.1365 & -1.10651 & 9.384126 & 2.724048 & -0.387 & -0.01401 & -3.77444 & -0.34587 \\
Maximum & 0.372146 & 3.724676 & 12.83254 & 8.42752 & 0.516766 & 0.086902 & 0.360077 & 0.268471 \\
Sum & -4.8772 & 20.00012 & 220.1515 & 104.9877 & 0.36224 & 0.281442 & -8.76415 & -0.17011 \\
Count & 20 & 20 & 20 & 20 & 20 & 20 & 20 & 20 \\
\hline
\end{tabular}

In the first data organization model "dataorg1", excess returns are regressed on beta, growth, value, earnings, and investments (Table 1). 
$\mathrm{EER} i=a 1 \mathrm{~B} i+\ln \left(\right.$ growth $\left.i^{a 2} \times \operatorname{size} i^{a 3}\right)+a 4($ earnings $i)+a 5($ investments $i)+\varepsilon i($ Dataorg 1$)$ where, in the cross section ${ }^{1}, i$ indexes firms; EER $i$ is excess returns; $B i$ is the quantity of the covariance, CAPM risk; growth $i$ is the risk quantity of the value-growth factor; size $i$ is the risk quantity of the small-large factor; earnings $i$ is the risk quantity of the high-low earnings factor; and $\varepsilon i$ is a Gauss-Markov error term.

To minimize standard errors, the model employs: (1) the natural logarithm of growth, measured as the lagged market value of equity; (2) the natural logarithm of size, measured as the lagged book value normalized by the lagged market value of equity; (3) earnings, measured as the lagged accounting earnings normalized by lagged book value; and (4) investments, measured as the contemporaneous change in the book value of equity normalized by lagged book value. Table 2 presents model statistics, Table 3 presents the analysis of variance, and Table 4 presents parameter estimates.

Table 2

Estimating "Dataorgl”, Summary

\begin{tabular}{ll}
\hline Model statistic & \\
\hline Multiple $R$ & 0.9719032 \\
$R$ square & 0.9445958 \\
Adjusted $R$ square & 0.9248086 \\
Standard error & 0.1003923 \\
Observations & 20 \\
\hline
\end{tabular}

Table 3

Estimating "Dataorgl”, ANOVA

\begin{tabular}{llllll}
\hline & df & SS & MS & $F$ & Significance $F$ \\
\hline Regression & 5 & 2.40565 & 0.48113 & 47.7376846 & $2.648 \mathrm{E}-08$ \\
Residual & 14 & 0.141101 & 0.010079 & & \\
Total & 19 & 2.546751 & & & \\
\hline
\end{tabular}

Table 4

Estimating "Dataorg1", Parameter Estimates \& Tests

\begin{tabular}{lllllll}
\hline & Coefficients & Standard error & $t$ stat & $P$-value & Lower 95\% & Upper 95\% \\
\hline Intercept & -0.413706 & 0.264387 & -1.56477 & 0.13995368 & -0.9807601 & 0.153348 \\
Beta & -0.3273672 & 0.023933 & -13.6782 & $1.7136 \mathrm{E}-09$ & -0.3786994 & -0.27603 \\
Growth & 0.0502963 & 0.025946 & 1.938475 & 0.07299674 & -0.005353 & 0.105946 \\
Value & -0.0115026 & 0.015345 & -0.74961 & 0.46589985 & -0.0444138 & 0.021409 \\
Earnings & 0.2922503 & 0.202143 & 1.445759 & 0.17025789 & -0.1413037 & 0.725804 \\
Investments & 0.1571918 & 0.280819 & 0.559762 & 0.58448696 & -0.4451046 & 0.759488 \\
\hline
\end{tabular}

The model is strongly significant at all conventional levels and has an explanatory power of more than $94 \%$. Beta's parameter estimate is negative and strongly significant at a 5\% type I error. This suggests a negative market risk premium, which reconciles well with a negative average market return of $-24 \%$ over the four-year study period. Growth's parameter estimate is positive, which suggests that the average Saudi investor

\footnotetext{
1 This is typical in asset pricing for excess returns focus the empirical analysis on risk premiums.
} 
requires higher returns for firms with higher market values (i.e., growth firms). Value's parameter estimate is negative, which suggests that the average Saudi investor requires lower returns for firms with higher book values (i.e., value firms). Earnings' parameter estimate is positive and suggests that the average Saudi investor requires higher returns for firms with higher book earnings. This may suggest that accounting conservatism tends to be priced favorably (see Basu, 1997). Investments' parameter estimate is positive and suggests that the average Saudi investor requires higher returns for firms with higher reported equity changes. This has direct information risk implications that are addressed in the second data organization model.

In the second data organization model "dataorg2", accounting earnings are decomposed into operating cash flows and accruals, and so excess returns are regressed on beta, growth, value, operating cash flows, accounting accruals, and investments.

$$
\mathrm{EER} i=a 1 \mathrm{~B} i+\ln \left(\text { growth } i^{a 2} \times \operatorname{size} i^{a 3}\right)+a 4(\text { cashflow })+a 5(\text { accruals })+a 6(\text { investments })+\varepsilon i(\text { Dataorg } 2)
$$

where cash flow is measured as lagged operating cash flows normalized by lagged book value; and accruals is measured as the lagged difference between operating cash flows and accounting earnings normalized by lagged book value. Table 5 presents model statistics, Table 6 presents the analysis of variance, and Table 7 presents parameter estimates.

Table 5

Estimating “Dataorg2”, Summary

\begin{tabular}{ll}
\hline Model statistic & \\
\hline Multiple $R$ & 0.979332 \\
$R$ square & 0.959091 \\
Adjusted $R$ square & 0.94021 \\
Standard error & 0.089522 \\
Observations & 20 \\
\hline
\end{tabular}

Table 6

Estimating “Dataorg2”, ANOVA

\begin{tabular}{llllll}
\hline & df & SS & MS & $F$ & Significance $F$ \\
\hline Regression & 6 & 2.442566 & 0.407094 & 50.79674 & $2.81 \mathrm{E}-08$ \\
Residual & 13 & 0.104184 & 0.008014 & & \\
Total & 19 & 2.546751 & & & \\
\hline
\end{tabular}

Table 7

Estimating “Dataorg2”, Parameter Estimates \& Tests

\begin{tabular}{lllllll}
\hline & Coefficients & Standard error & $t$ stat & $P$-value & Lower 95\% & Upper 95\% \\
\hline Intercept & -0.15659 & 0.266029 & -0.58862 & 0.566204 & -0.73131 & 0.418131 \\
Beta & -0.32307 & 0.021607 & -14.9523 & $1.44 \mathrm{E}-09$ & -0.36975 & -0.27639 \\
Growth & 0.033558 & 0.02458 & 1.365261 & 0.195332 & -0.01954 & 0.086659 \\
Value & -0.02079 & 0.01436 & -1.44806 & 0.171287 & -0.05182 & 0.010229 \\
Cash flow & 0.118441 & 0.200243 & 0.591487 & 0.564338 & -0.31416 & 0.551041 \\
Accruals & -0.72991 & 0.27205 & -2.68299 & 0.018793 & -1.31764 & -0.14218 \\
Investments & -0.10185 & 0.278075 & -0.36629 & 0.720044 & -0.7026 & 0.49889 \\
\hline
\end{tabular}


The model is strongly significant at all conventional levels and has an explanatory power of nearly $95 \%$. Still Beta's parameter estimate is negative and strongly significant at a 5\% type I error. This replicates well the negative average market return as mentioned above. The parameter estimates for both "growth" and "value" still have the same direction as their respective counterparts in "dataorg1". However, when the coarse accounting earnings are disintegrated into cash flows and accruals, cash flows pick a positive parameter estimate and accruals pick a negative one. Furthermore, unlike that in "dataorg1", investments in "dataorg2" have a negative parameter estimate. This suggests that, when earnings' components are replicated individually in the empirical pricing model, the average Saudi investor requires lower returns for firms with higher investments and hence prices those investments favorably. This stands in great contrast with "dataorg1" where only the total accounting earnings are priced and that the average investor's only answer to the inherent information risk underlying the rather coarse measure is to price investments unfavorably via requiring higher returns for firms with higher investments. When cash flows and accruals are individually priced, it is as if the investor prices aggressive firms favorably and conservative firms unfavorably. The investor also requires higher returns for firms with higher cash flows and lesser returns for firms with higher accounting accruals. The investor hence prices accruals favorably and cash flows unfavorably.

\section{Empirical Study and Tests (APT)}

"Empirical research is (or should be) informed by theory, since interpretations of empirical analysis is impossible without theoretical guidance" (Kothari, 2002, p. 1). In this context, Ross' APT (1976a; 1976b) defined the theoretical framework for this study. Both estimated versions of the parsimonious proxy model are APT specifications and so is satisfied the theoretical framework necessary for a quantitative study.

Fama and French (2015) organized market data with no underlying theoretical framework. Their five-factor model is thus an outcome of an inductive study. APT, however, is a testable and asset pricing theory, but the risk drivers are not identified. APT simply shows that there exists more than one priced risk driver, and so, as opposed to the CAPM, there is more to explain the contemporaneous variation in excess returns than just the systematic risk, beta. Fama and French's model (2015) is thus consistent with APT. The heart of this study is to use APT as a theoretical framework in order to test the five-factor model. On one hand, the five-factor model is based on factors (i.e., risk premiums), which are not asset specific. On the other hand, APT is based on state variables, which are asset specific (e.g., the systematic risk, beta). Accordingly, state proxies are ought to be used in the tests so as to purport to the respective factor model's risk premiums. In this concern, "dataorg1" uses "beta" as a state variable that purports to market risk premium. By the same token, "growth" is used as a state variable that purports to a portfolio premium that is short in firms with big market size and long in firms with small market size (i.e., SMB); "value" is used as a state variable that purports to a portfolio premium that is short in firms with low value and long in firms with high value (i.e., HML); "earnings" is used as a state variable that purports to a portfolio premium that is short in firms with low earnings and long in firms with high earnings (i.e., the earnings premium); and "investments" is used as a state variable that purports to a portfolio premium that is short in firms with low investments and long in firms with high investments (i.e., the investments risk premium). In "dataorg2", "operating cash flows" is also used as a state variable that purports to a portfolio premium that is short in firms with low cash flows and long in firms with high cash flows; and "accounting accruals" is used as a state variable that purports to a portfolio premium that is short in firms with low accounting accruals and long in firms with high accounting accruals. 
With APT serving as theoretical framework, "dataorg1" can be interpreted as a restricted parsimony and "dataorg2" can be interpreted as an unrestricted parsimony.

The restricted parsimony, "dataorg1", strongly explains the variation in average returns in the study sample. The explanatory power is more than $94 \%$. The direction of parameter estimates replicates the predictions from prior, influential studies (e.g., Fama \& French, 1995). Prior empirical asset pricing studies consider interpreting the magnitude of parameter estimates an ambitious apparatus. With APT as a theoretical framework, the respective magnitudes of "dataorg1" stand with contrast to their (Fama \& French, 1993) counterparts. Unlike Fama and French (1993) where beta is replaced altogether by value and growth, beta in "dataorg1" is strongly significant at all conventional levels and successfully replaces value, growth, earnings, and investments all together. A possible explanation here is that over this study's sample, value, growth, earnings, and investments are all reasonable covariates of book value, which does not add significant pricing news over the covariance risk.

The unrestricted parsimony, "dataorg2", also strongly explains the variation in average returns in the study sample. The explanatory power is almost $96 \%$. The direction of parameter estimates is the same as in "dataorg1" except for investments. When accounting earnings are decomposed into cash flows and accruals, cash flows retain the sign of earnings and both are priced unfavorably. Accruals, however, pick a negative and significant parameter estimate at the $5 \%$ level and are priced favorably along with investments. A possible story here is that when the components of accounting earnings are replicated individually in the empirical pricing model estimated over the study sample, the average investor shows his ultimate concerns with future cash flows by focusing on accruals and not cash flows. Unlike cash flows, accounting accruals are documented to provide reliable signals regarding future cash flows and hence average returns via the advantage of an exercise of management discretion in terms of conveying private information to investors (Kothari, 2002; Dechow, 1994). Dechow, Richardson, and Sloan (2008) also explained that accounting accruals reduce timing and mismatching problems in cash flows. This is paramount for asset pricing. With accruals priced individually, the average Saudi investor tends to price investments favorably though not significantly.

Based on the preceding, "dataorg1" and "dataorg2" reduce, significance wise, to a third parsimony, parsimonious specification (PS) that specifies average returns in terms of the covariance risk and accounting accruals:

$$
\mathrm{EER} i=a 1 \mathrm{~B} i+a 2(\text { accruals })+\varepsilon i(\mathrm{PS})
$$

Table 8 presents model statistics, Table 9 presents the analysis of variance, and Table 10 presents parameter estimates.

Table 8

Estimating PS, Summary

\begin{tabular}{ll}
\hline Model statistic & \\
\hline Multiple $R$ & 0.974104836 \\
$R$ square & 0.948880231 \\
Adjusted $R$ square & 0.94286614 \\
Standard error & 0.087511109 \\
Observations & 20 \\
\hline
\end{tabular}


Table 9

Estimating PS, ANOVA

\begin{tabular}{llllll}
\hline & $\mathrm{df}$ & SS & MS & $F$ & Significance $F$ \\
\hline Regression & 2 & 2.416561 & 1.208281 & 157.7761816 & $1.05 \mathrm{E}-11$ \\
Residual & 17 & 0.130189 & 0.007658 & & \\
Total & 19 & 2.546751 & & & \\
\hline
\end{tabular}

Table 10

Estimating PS, Parameter Estimates \& Tests

\begin{tabular}{lllllll}
\hline & Coefficients & Standard error & $t$ stat & $P$-value & Lower 95\% & Upper 95\% \\
\hline Intercept & 0.094217906 & 0.027713 & 3.399772 & 0.00340946 & 0.035749 & 0.152687 \\
Beta & -0.310192209 & 0.017633 & -17.592 & $2.4085 \mathrm{E}-12$ & -0.34739 & -0.27299 \\
Accruals & -0.619559706 & 0.164402 & -3.76856 & 0.001531913 & -0.96642 & -0.2727 \\
\hline
\end{tabular}

PS is strongly significant with an explanatory power of almost $95 \%$. The parameter estimates of beta and accounting accruals are both strongly significant at all conventional levels. PS suggests that in addition to the systematic risk, the investor prices the firm-specific private information that management conveys to investors via accounting accruals. Accounting accruals thus mitigate the information risk by picking a negative sign. In the spirit of Fama and French, PS suggests that growth, value, cash flows, and investments are redundant and that a two-factor model of the covariance risk and accounting accruals performs as well as the six-factor model estimated by the unrestricted version. Future asset pricing research may regard PS as empirical APT evidence that is qualified by both the market and the sample analyzed in this study.

\section{Conclusions}

Proxy asset pricing specifications, though intuitively appealing, are scant due to lack of theoretical frameworks and misguided significance tests of factor loadings. Nevertheless, the empirical analysis may extend beyond describing market facts and into testing an APT model. This is so since APT is a testable asset pricing theory where the risk factors are not identified. APT simply states that there exists more than one priced risk driver, and so, as opposed to the CAPM, there is more to explain the contemporaneous variation in excess returns than just the systematic risk beta. Factor models are thus consistent with APT.

The study estimates two proxy versions of Fama and French's five-factor model (2015) to produce stylized facts of the Saudi capital market and test an APT model. The study in this fashion adheres to a step-wise design and progressed in two steps: (1) estimating the two versions based on whether accounting earnings were replicated in total or decomposed into cash flows and accruals; and (2) testing the two versions as APT parsimonious specifications.

The final outcome of the study is a significant empirical specification that explains average returns in terms of the covariance risk and accounting accruals where the parameter estimates are robust at all conventional levels. Exogenously, accounting accruals may be interpreted as a measure of the firm-specific information risk faced by investors. The specification suggests that in addition to the systematic risk, the investor prices private information that management conveys via accounting accruals, which is both firm-specific and one that mitigates the information risk. In the spirit of Fama and French $(1993 ; 1995 ; 2015)$, the concluding specification suggests that growth, value, cash flows, and investments are redundant and that a two-factor model of beta and accruals performs as well as the six-factor model estimated by the unrestricted 
version. Future asset pricing research may regard the specification as empirical evidence within an APT theoretical framework and one that is qualified by both the KSA market and the sample studied in this paper.

\section{References}

Banz, R. W. (1981). The relationship between return and market value of common stock. Journal of Financial Economics, 9 , $3-18$.

Basu, S. (1977). Investment performance of common stock in relation to their price-earnings ratios-A test of the efficient market hypothesis. The Journal of Finance, 32, 663-682.

Black, F. (1972). Capital market equilibrium with restricted borrowing. Journal of Business, 45, 444-454.

Black, F., Jensen, M. C., \& Scholes, M. (1972). The capital asset pricing model: Some empirical tests. In M. C. Jensen (Ed.), Studies in the theories of capital markets (1st ed.). New York: Praeger.

Cohen, R., Gompers, P., \& Vuolteenaho, T. (2002). Who underreacts to cashflow news? Evidence from trading between individuals and institutions. Journal of Financial Economics, 66, 409-462.

Dechow, P. (1994). Accounting earnings and cash flows as measures of firm performance: The role of accounting accruals. Journal of Accounting and Economics, 18, 3-42.

Dechow, P., Richardson, S., \& Sloan, R. (2004). The persistence and pricing of the cash component of earnings. Journal of Accounting Research, 46, 537-566.

Fama, F. E., \& French, K. R. (1993). Common risk factors in the returns on stocks and bonds. Journal of Financial Economics, 33, 3-56.

Fama, F. E., \& French, K. R. (1995). Size and book-to-market factors in earnings and returns. Journal of Finance, 50, $131-156$.

Fama, F. E., \& French, K. R. (2006). Profitability, investment, and average returns. Journal of Financial Economics, 82, $491-518$.

Fama, F. E., \& French, K. R. (2008). Dissecting anomalies. The Journal of Finance, 63, 1653-1678.

Fama, F. E., \& French, K. R. (2015). A five-factor asset pricing model. Journal of Financial Economics, 116, 1-22.

Gibbons, M. R. (1982). Multivariate tests of financial models: A new approach. Journal of Financial Economics, 10, 3-27.

Gibbons, M., Ross, S., \& Shanken, J. (1989). A test of the efficiency of a given portfolio. Econometrica, 57, 1121-1152.

Haugen, R., \& Baker, N. (1996). Commonality in the determinants of expected stock returns. Journal of Financial Economics, 41, 401-439.

Kothari, S. (2002). Capital market research in accounting. Journal of Accounting and Economics, 31(1), 105-231.

Litzenberger, R., \& Ramaswamy, K. (1979). The effect of personal taxes and dividends on capital asset prices: Theory and empirical evidence. Journal of Financial Economics, 7, 114-164.

Merton, R. (1973). An intertemporal capital asset pricing model. Econometrica, 41, 867-887.

Reinganum, M. R. (1981). Misspecification of capital asset pricing: Empirical anomalies based on earnings' yields and market values. Journal of Financial Economics, 9, 19-46.

Rosenberg, B., \& Marathe, V. (1979). Tests of capital asset pricing hypotheses. Research in Finance, 1, 4-15.

Ross, S. A. (1976a). Return, risk and arbitrage. In I. Friend and J. L. Bicksler (Eds.), Risk and return in finance (1st ed.). Cambridge, Mass.: Ballinger.

Ross, S. A. (1976b). The arbitrage theory of capital asset pricing. Journal of Economic Theory, 13, 341-360.

Sharpe, W. F. (1964). Capital asset pricing-A theory of market equiblibrium under conditions of risk. Journal of Finance, 3 , 425-442.

Titman, S., Wei, K., \& Xie, F. (2004). Capital investments and stock returns. Journal of Financial and Quantitative Analysis, 39 , 677-700. 